\title{
Effect of BMI on Foot Dimensions in Different Weight Bearing Conditions of Obokwe Indigenes in Imo State
}

\author{
Bob-Manuel, Ibinabo. Fubara ${ }^{1 *}$, Ogoun, Timipa Richard ${ }^{2}$ \\ ${ }^{1}$ Department of Anatomy, Faculty of Basic Medical Sciences, College of Health Sciences, \\ University of Port Harcourt, P.M.B 5323, Port Harcourt, Rivers State \\ 2Department of Anatomy, Faculty of Basic Medical Sciences, College of Health Sciences, \\ Bayelsa Medical University, Yenegoa, Bayelsa State \\ *Corresponding author details: Bob-Manuel, Ibinabo. Fubara; \\ ibinabo.bob-manuel@uniport.edu.ng
}

\begin{abstract}
The understanding of the effect of BMI on foot dimensions under different weight bearing conditions can help in the design and production of a comfortable and efficient foot support. This study is aimed at using Body Mass Index (BMI) to correlate the foot dimensions of males and females under different weight bearing conditions. The foot dimensions of 320 subjects (160 males and 160 females) between the age range of 19 and above with normal foot were measured under three weight bearing conditions: non-weight bearing, semi-weight bearing, and full-weight bearing. Height, weight and BMI of the individuals were recorded. The data collected was analysed using SPSS software version (20). Paired sample t-test and Pearson correlation coefficient test was done for calculating the statistical significance. The change in foot breadth of semi-weight bearing condition (FBSN) produced a significant correlation with BMI $(\mathrm{p}<0.05)$ but that with Foot length (FLSN) and Arch height (AHSN) was not statistically significant for the males. Also, the change in Foot length of full weight bearing condition (FLFN), Foot breadth (FBFN) and Arch height (AHFN) was not statistically significant for the males. There was significant correlation between BMI and the change in foot dimensions such as FLFN, AHSN, AHFN $(\mathrm{p}<0.05)$ but that with FLSN, FBSN and FBFN was not statistically significant for the females. Not all foot dimensions can be significantly influenced by BMI. This study is useful in considering the effect of BMI in the change of foot shape in weight-bearing during the selection of shoe size and shoe or insole design and construction and to the orthotics during the design of fitting devices for foot support. Also, it can be useful in forensic science.
\end{abstract}

Keywords: body mass index; foot length; arch height; foot breadth; weight-bearing; forensic science

\section{INTRODUCTION}

There are indications that Body Mass Index (BMI) can effectively influence the foot dimensions such as foot length, foot breadth and arch height under different weight bearing conditions. Body mass index is a heuristic measure of body weight based on an individual's weight and height. Though it does not actually measure the percentage of body fat, it is used to estimate a healthy body weight based on an individual's height assuming an average body composition. Due to its ease of measurement and calculation, it is the most widely used diagnostic tool to identify weight problems within a population, usually whether individuals are underweight, overweight or obese (Keys et al., 1972). The prevalence of adults who are overweight or obese is increasing and figures suggest these adults represent 10$30 \%$ of the global population (WHO, 2014). It is important that these populations are physically active as part of weight management programmes and to improve cardiovascular health (WHO, 2014), which demands appropriate and comfortable footwear.

Anthropometry deals with the measurement of physical sizes and shapes of human body. At its most basic, anthropometrics is used to help scientists and anthropologists understand physical variations among humans. Foot anthropometry is the measurement of the size and proportion of the human foot. Parameters most often measured include foot length and foot breadth. The foot gives support to the body in standing, resilience for walking and adaptation to variations of surfaces on which it is placed. The normal human foot for both males and females shows great individual variation in length and breadth (Richards, 2000). Shoes and insoles have been designed to protect the foot and facilitate proper functioning of the foot for daily activities. How well the shoes and insoles fit with the foot shape is an important determinant for a functional and comfortable foot support. Studies on the anthropometry of foot shape used different protocols and measurement devices. Most easy methods to directly measure the foot length, breadth, height and girth dimensions includes the use of venier calipers (digital and manual), metre rule, measuring tape etc. Others measured from footprint. Alternatively, measurements are taken using a 3D scanner and have high validity, repeatability and automatically quantify standard measurements required for last manufacture and the definition of footwear.

Studies using the impression casting protocol of the foot under three different weight conditions found that increased weight bearing significantly measured the contact area, foot length, foot width and rear foot width, 
while it decreased average height and arch angle (Bonnie et al., 2003). Compared with the non-weight bearing foot shape, the semi-weight bearing condition would produce increases in foot length of $2.7 \% \pm 1.2 \%$, foot width of $2.9 \%$ $\pm 2.4 \%$. The full weight bearing condition would produce increases in foot length of $3.4 \% \pm 3.1 \%$, foot width of $6.0 \%$ $\pm 2.1 \%$. These researches using the foot digitizing and impression casting protocol avoids the error caused by skin displacement and tissue distortion.

An organized review has also identified relationships between increased body mass index (BMI) and tendonitis and flat foot (Butterworth et al., 2012). Furthermore, obese adults also report reduced satisfaction with retail footwear and that it becomes increasingly difficult to find comfortable and appropriate footwear as BMI increases (Jelinek and Fox, 2009; Park, 2012). This may be attributable to morphological and dimensional variances between the obese foot and the standard and wide-fit retail footwear designed to accommodate it (Price and Nester, 2015). The foot of an adult who is obese may differ in structure and function compared with the foot of a healthy weight individual due to alterations in morphology, soft tissue properties and functional capability (Dowling et al., 2001; Hills et al., 2002; Riddiford-Harland et al., 2011). Specifically, lower longitudinal arch heights (Gilmour and Burns, 2001; Gravante et al., 2003; Mickle et al., 2006) and greater foot lengths and girths (Mickle et al., 2006; Mickle and Steele, 2015; Park, 2012) are evident in the feet of adults and children who are obese compared with healthy controls. The morphology and function of the feet of adults who are overweight are yet to be widely and thoroughly investigated independently from obese populations as some work does not differentiate overweight and obese individuals (Mauch et al., 2008).

The foot dimensions corresponding to different weight bearing conditions at different BMI are believed to be distinctive and can provide a broader description of the footinsole interaction when considering foot biomechanics. Therefore, the need to understand the foot dimensions and its change under different weight bearing and to determine which foot shape would best be adopted as the deciding factor in designing the support shape for better fit and comfort (Bonnie et al., 2013).

\section{MATERIALS AND METHODS:}

A total of three hundred and twenty (320) subjects (160 males and 160 females) between 19 years and above were used for this study. The parameters measured from each foot are the foot length, foot breadth and arch height at the different weight bearing conditions: non-weight bearing, semi-weight bearing and full-weight bearing. Also, the height and weight of each subject was measured to determine the BMI. The height of each subject was measured as the vertical distance from the most inferior part of the heel of the foot to the vertex of the head. It was measured by using a standiometer. The weight of the subjects was measured using a weighing balance.

TABLE 1: International Classification of adult underweight, overweight and obesity according to BMI.

\begin{tabular}{|c|c|c|}
\hline \multirow[t]{2}{*}{ Classification } & \multicolumn{2}{|c|}{ BMI $(\mathrm{kg} / \mathrm{m} \vartheta)$} \\
\hline & Principal cut-off points & Additional cut-off points \\
\hline Underweight & $<18.50$ & $<18.50$ \\
\hline Severe thinness & $<16.00$ & $<16.00$ \\
\hline Moderate thinness & $16.00-16.99$ & $16.00-16.99$ \\
\hline Mild thinness & $17.00-18.49$ & $17.00-18.49$ \\
\hline \multirow{2}{*}{ Normal range } & \multirow{2}{*}{$18.50-24.99$} & $18.50-22.99$ \\
\hline & & $23.00-24.99$ \\
\hline Overweight & $\geq 25.00$ & $\geq 25.00$ \\
\hline \multirow{2}{*}{ Pre-obese } & \multirow{2}{*}{$25.00-29.99$} & $25.00-27.49$ \\
\hline & & $27.50-29.99$ \\
\hline Obese & $\geq 30.00$ & $\geq 30.00$ \\
\hline \multirow{2}{*}{ Obese class I } & \multirow{2}{*}{$30.00-34-99$} & $30.00-32.49$ \\
\hline & & $32.50-34.99$ \\
\hline \multirow{2}{*}{ Obese class II } & \multirow{2}{*}{$35.00-39.99$} & $35.00-37.49$ \\
\hline & & $37.50-39.99$ \\
\hline Obese class III & $\geq 40.00$ & $\geq 40.00$ \\
\hline
\end{tabular}

Body Mass Index (BMI): The BMI is defined as the body mass divided by the square of the body height, and is universally expressed in units of $\mathrm{kg} / \mathrm{m}^{2}$, resulting from mass in kilograms and height in meters i.e $\mathrm{W} / \mathrm{H}^{2}$. Below are the classification and ranges according to WHO.

For this study, the direct measurement technique was employed to investigate the foot shape changes under different weight bearing conditions. The foot dimensions were measured directly using a sliding Venier calipers with the foot placed on a horizontal flat surface at three weight bearing conditions i.e. non-weight bearing (NWB), semi-weight bearing (SWB) and full-weight bearing (FWB). The foot lengths were measured from the most posterior projection of the heel (akropodion) to the most anterior toe (pternion). The foot breadths were measured from the most medially placed point on the head of 1 st metatarsal to the most laterally placed point located on the head of 5 th metatarsal. Arch height was measured from $1 / 2$ the foot length as the distance between the sole of the feet to the dorsal arch.

The measurements of the foot dimension were taken under the NWB, SWB and FWB. For the non-weight bearing condition, measurements were done with the subject sitting without body weight bearing on the foot measured. The knee and ankle were kept at 90\% flexion, and the centers of both heels were separated by the width of the subject's shoulder. The lines of projection of both feet were kept parallel and pointing forward. Measurements for semi-weight bearing were taken with half the body weight placed on the measured foot, with the line of progression of both feet parallel to each other and pointing forward. 
This was achieved by instructing the subjects to stand upright, with the distance between the two heels centers kept apart at the width of subject's shoulder.
For the full-weight bearing (FWB), measurements were taken with the full body weight placed on the foot measured. This was achieved by instructing the subject to stand upright on the measured foot. The foot not measured is flexed up and bore no weight. The line progression of the foot measured pointing forward.

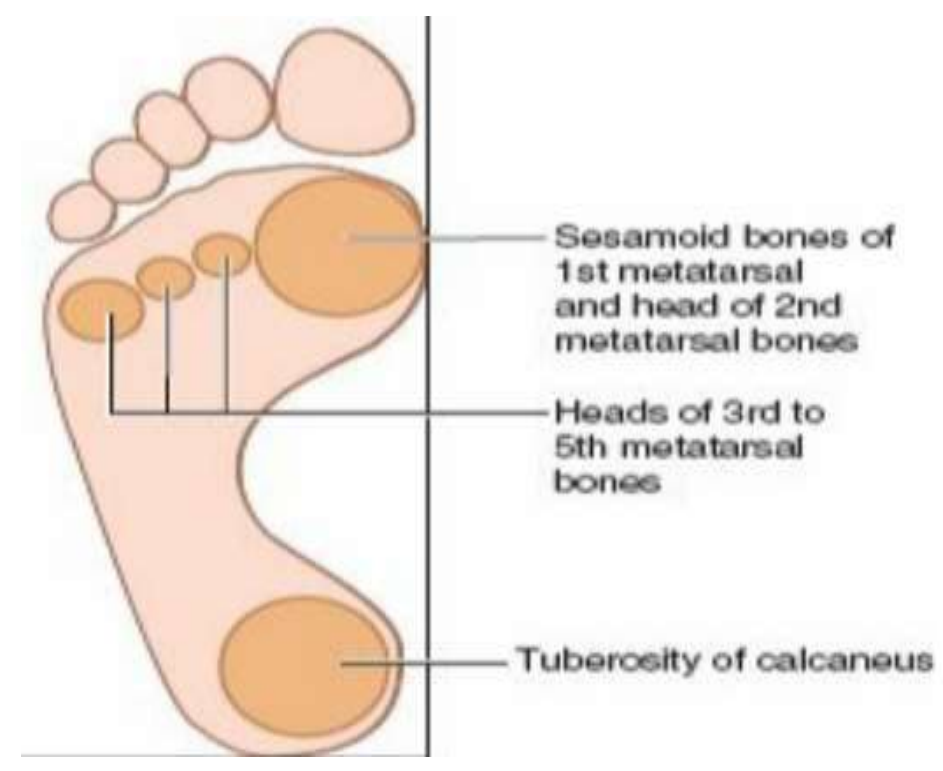

FIGURE 1: Weight bearing areas of the foot (Moore et al., 2014)

\section{RESULTS}

The results of the study are shown in tables below.

The age groups and number of individuals in each group for both male and female are represented in table 2.

TABLE 2: Sample size and age distribution of subjects

\begin{tabular}{ccc}
\cline { 2 - 3 } & \multicolumn{2}{c}{ No. of Individuals } \\
\hline Age Group & Males & Females \\
\hline $19-35$ & 72 & 68 \\
$36-50$ & 48 & 48 \\
$51-65$ & 40 & 44 \\
\hline Total & 160 & 160 \\
\hline
\end{tabular}

TABLE 3: Descriptive Statistics for Females

\begin{tabular}{lcc}
\hline & FEMALES & \\
\hline PARAMETERS & Mean \pm SD & RANGE \\
\hline Height (m) & $1.68 \pm 0.09$ & $1.57-1.88$ \\
Weight (kg) & $69.25 \pm 9.03$ & $55.00-87.00$ \\
BMI (kg/m2) & $24.69 \pm 3.88$ & $16.87-32.39$ \\
FLN (cm) & $25.41 \pm 1.20$ & $24.19-28.07$ \\
FLS (cm) & $25.67 \pm 1.22$ & $24.36-28.50$ \\
FLF (cm) & $25.85 \pm 1.23$ & $24.45-28.63$ \\
FBN (cm) & $8.86 \pm 0.41$ & $8.04-9.53$ \\
FBS (cm) & $9.06 \pm 0.39$ & $8.23-9.77$ \\
FBF (cm) & $9.93 \pm 0.40$ & $8.40-9.93$ \\
AHN (cm) & $6.86 \pm 0.34$ & $6.42-7.78$ \\
AHS (cm) & $6.66 \pm 0.36$ & $6.10-7.50$ \\
AHF (cm) & $6.62 \pm 0.68$ & $6.01-9.17$ \\
\hline
\end{tabular}

FLN = Foot length for Non-weight bearing; FLS= Foot length for Semi-weight bearing; FLF= Foot length for Full-weight bearing. FBN = Foot breadth for Non-weight bearing; FBS= Foot breadth for Semi-weight bearing; FBF= Foot breadth for Full-weight bearing. AHN = Arch Height for Non-weight bearing; $A H S=$ Arch Height for Semi-weight bearing; $A H F=$ Foot length for Full-weight bearing; $S D=$ Standard Deviation. 
TABLE 4: Descriptive Statistics for Males.

\begin{tabular}{lcc}
\hline & MALES & \\
\hline PARAMETERS & Mean \pm SD & RANGE \\
\hline Height (m) & $1.77 \pm 0.08$ & $1.63-1.96$ \\
Weight (kg) & $75.18 \pm 6.44$ & $59.00-85.00$ \\
BMI (kg/m2) & $24.19 \pm 2.58$ & $20.42-31.62$ \\
FLN (cm) & $27.49 \pm 1.68$ & $23.15-30.12$ \\
FLS (cm) & $27.84 \pm 1.60$ & $23.76-30.34$ \\
FLF (cm) & $28.05 \pm 1.57$ & $24.40-30.44$ \\
FBN (cm) & $9.52 \pm 0.53$ & $8.22-11.20$ \\
FBS (cm) & $9.75 \pm 0.50$ & $8.75-11.43$ \\
FBF (cm) & $9.87 \pm 0.49$ & $8.97-11.56$ \\
AHN (cm) & $7.45 \pm 0.55$ & $6.55-8.83$ \\
AHS (cm) & $7.26 \pm 0.55$ & $6.46-8.71$ \\
AHF (cm) & $7.10 \pm 0.53$ & $6.22-8.40$ \\
\hline
\end{tabular}

FLN = Foot length for Non-weight bearing; FLS= Foot length for Semi-weight bearing; FLF= Foot length for Full-weight bearing. FBN = Foot breadth for Non-weight bearing; FBS= Foot breadth for Semi-weight bearing; FBF= Foot breadth for Full-weight bearing. AHN = Arch Height for Non-weight bearing; $A H S=$ Arch Height for Semi-weight bearing; AHF= Foot length for Full-weight bearing; $S D=$ Standard Deviation.

TABLE 5: Pearson Correlation co-efficient of BMI and Change in foot dimensions of Females

\begin{tabular}{|c|c|c|c|c|c|c|c|c|c|c|}
\hline \multicolumn{11}{|c|}{ Correlations } \\
\hline & & HEIGHTf & WEIGHTf & BMIf & FLSNf & FLFNf & FBSNf & FBFNf & AHSNf & AHFNf \\
\hline \multirow{3}{*}{ HEIGHTf } & $\begin{array}{c}\text { Pearson } \\
\text { Correlation }\end{array}$ & 1 & .064 & $-.535^{* *}$ & .208 & .178 & .169 & .233 & .030 & -.095 \\
\hline & Sig. (2-tailed) & & .693 & .000 & .198 & .272 & .296 & .148 & .856 & .559 \\
\hline & $\mathrm{N}$ & 160 & 160 & 160 & 160 & 160 & 160 & 160 & 160 & 160 \\
\hline \multirow{3}{*}{ WEIGHTf } & $\begin{array}{c}\text { Pearson } \\
\text { Correlation }\end{array}$ & .064 & 1 & $.805^{* *}$ & $.464^{* *}$ & $.574^{* *}$ & .193 & .166 & $-.663^{* *}$ & $.400^{*}$ \\
\hline & Sig. (2-tailed) & .693 & & .000 & .003 & .000 & .232 & .305 & .000 & .010 \\
\hline & $\mathrm{N}$ & 160 & 160 & 160 & 160 & 160 & 160 & 160 & 160 & 160 \\
\hline \multirow{3}{*}{ BMIf } & $\begin{array}{c}\text { Pearson } \\
\text { Correlation }\end{array}$ & $-.535^{* *}$ & $.805^{* *}$ & 1 & .279 & $.396^{*}$ & .060 & .007 & $-.582^{* *}$ & $.394^{*}$ \\
\hline & Sig. (2-tailed) & .000 & .000 & & .082 & .011 & .713 & .965 & .000 & .012 \\
\hline & $\mathrm{N}$ & 160 & 160 & 160 & 160 & 160 & 160 & 160 & 160 & 160 \\
\hline \multirow{3}{*}{ FLSNf } & $\begin{array}{c}\text { Pearson } \\
\text { Correlation }\end{array}$ & .208 & $.464^{* *}$ & .279 & 1 & $.889^{* *}$ & $.587^{* *}$ & $.596^{* *}$ & $-.314^{*}$ & .116 \\
\hline & Sig. (2-tailed) & .198 & .003 & .082 & & .000 & .000 & .000 & .048 & .474 \\
\hline & $\mathrm{N}$ & 160 & 160 & 160 & 160 & 160 & 160 & 160 & 160 & 160 \\
\hline \multirow{3}{*}{ FLFNf } & $\begin{array}{c}\text { Pearson } \\
\text { Correlation }\end{array}$ & .178 & $.574^{* *}$ & $.396^{*}$ & $.889^{* *}$ & 1 & $.469^{* *}$ & $.483^{* *}$ & -.281 & .139 \\
\hline & Sig. (2-tailed) & .272 & .000 & .011 & .000 & & .002 & .002 & .079 & .394 \\
\hline & $\mathrm{N}$ & 160 & 160 & 160 & 160 & 160 & 160 & 160 & 160 & 160 \\
\hline \multirow{3}{*}{ FBSNf } & $\begin{array}{c}\text { Pearson } \\
\text { Correlation }\end{array}$ & .169 & .193 & .060 & $.587^{* *}$ & $.469^{* *}$ & 1 & $.951^{* *}$ & -.206 & .250 \\
\hline & Sig. (2-tailed) & .296 & .232 & .713 & .000 & .002 & & .000 & .203 & .120 \\
\hline & $\mathrm{N}$ & 160 & 160 & 160 & 160 & 160 & 160 & 160 & 160 & 160 \\
\hline \multirow{3}{*}{ FBFNf } & $\begin{array}{c}\text { Pearson } \\
\text { Correlation }\end{array}$ & .233 & .166 & .007 & $.596^{* *}$ & $.483^{* *}$ & $.951^{* *}$ & 1 & -.164 & .184 \\
\hline & Sig. (2-tailed) & .148 & .305 & .965 & .000 & .002 & .000 & & .312 & .255 \\
\hline & $\mathrm{N}$ & 160 & 160 & 160 & 160 & 160 & 160 & 160 & 160 & 160 \\
\hline \multirow{3}{*}{ AHSNf } & $\begin{array}{c}\text { Pearson } \\
\text { Correlation }\end{array}$ & .030 & $-.663^{* *}$ & $-.582^{* *}$ & $-.314^{*}$ & -.281 & -.206 & -.164 & 1 & $-.577^{* *}$ \\
\hline & Sig. (2-tailed) & .856 & .000 & .000 & .048 & .079 & .203 & .312 & & .000 \\
\hline & $\mathrm{N}$ & 160 & 160 & 160 & 160 & 160 & 160 & 160 & 160 & 160 \\
\hline \multirow{3}{*}{ AHFNf } & $\begin{array}{c}\text { Pearson } \\
\text { Correlation } \\
\end{array}$ & -.095 & $.400^{*}$ & $.394^{*}$ & .116 & .139 & .250 & .184 & $-.577^{* *}$ & 1 \\
\hline & Sig. (2-tailed) & .559 & .010 & .012 & .474 & .394 & .120 & .255 & .000 & \\
\hline & $\mathrm{N}$ & 160 & 160 & 160 & 160 & 160 & 160 & 160 & 160 & 160 \\
\hline
\end{tabular}


$N=$ distribution; BMI=Body Mass Index; FLN=Foot length non-weight bearing; FLS=Foot length semi-weight bearing; FLF=Foot length full-weight bearing; FLSN=change in foot length of semi-weight bearing condition; FLFN=change in foot breadth of fullweight bearing condition; $F B=$ Foot breadth; $A H=$ Arch Height; $f=$ female

TABLE 6: Pearson Correlation co-efficient of BMI and Change in foot dimensions of Males

\begin{tabular}{|c|c|c|c|c|c|c|c|c|c|c|}
\hline \multicolumn{11}{|c|}{ Correlations } \\
\hline & & HEIGHTm & WEIGHTm & BMIm & FLSNm & FLFNm & FBSNm & FBFNm & AHSNm & AHFNm \\
\hline \multirow{3}{*}{ HEIGHTm } & $\begin{array}{c}\text { Pearson } \\
\text { Correlation }\end{array}$ & 1 & $.321^{*}$ & $\begin{array}{c}- \\
.577^{* *} \\
\end{array}$ & -.011 & -.023 & -.104 & -.132 & -.050 & -.294 \\
\hline & $\begin{array}{c}\text { Sig. } \\
\text { (2-tailed) }\end{array}$ & & .044 & .000 & .948 & .887 & .522 & .417 & .761 & .066 \\
\hline & $\mathrm{N}$ & 160 & 160 & 160 & 160 & 160 & 160 & 160 & 160 & 160 \\
\hline \multirow{3}{*}{$\begin{array}{l}\text { WEIGHT } \\
\mathrm{m}\end{array}$} & $\begin{array}{c}\text { Pearson } \\
\text { Correlation }\end{array}$ & $.321^{*}$ & 1 & $.585^{* *}$ & .065 & .094 & $.319^{*}$ & .213 & -.248 & $-.456^{* *}$ \\
\hline & $\begin{array}{c}\text { Sig. } \\
\text { (2-tailed) }\end{array}$ & .044 & & .000 & .691 & .563 & .045 & .186 & .124 & .003 \\
\hline & $\mathrm{N}$ & 160 & 160 & 160 & 160 & 160 & 160 & 160 & 160 & 160 \\
\hline \multirow{3}{*}{ BMIm } & $\begin{array}{c}\text { Pearson } \\
\text { Correlation }\end{array}$ & $-.577^{* *}$ & $.585^{* *}$ & 1 & .076 & .112 & $.367^{*}$ & .300 & -.160 & -.130 \\
\hline & $\begin{array}{c}\text { Sig. } \\
\text { (2-tailed) }\end{array}$ & .000 & .000 & & .640 & .490 & .020 & .060 & .325 & .425 \\
\hline & $\mathrm{N}$ & 160 & 160 & 160 & 160 & 160 & 160 & 160 & 160 & 160 \\
\hline \multirow{3}{*}{ FLSNm } & $\begin{array}{c}\text { Pearson } \\
\text { Correlation }\end{array}$ & -.011 & .065 & .076 & 1 & $.980^{* *}$ & .166 & .151 & -.011 & .086 \\
\hline & $\begin{array}{c}\text { Sig. } \\
\text { (2-tailed) }\end{array}$ & .948 & .691 & .640 & & .000 & .307 & .352 & .949 & .600 \\
\hline & $\mathrm{N}$ & 160 & 160 & 160 & 160 & 160 & 160 & 160 & 160 & 160 \\
\hline \multirow{3}{*}{ FLFNm } & $\begin{array}{c}\text { Pearson } \\
\text { Correlation }\end{array}$ & -.023 & .094 & .112 & $.980^{* *}$ & 1 & .221 & .230 & .052 & .056 \\
\hline & $\begin{array}{c}\text { Sig. } \\
\text { (2-tailed) }\end{array}$ & .887 & .563 & .490 & .000 & & .170 & .154 & .749 & .733 \\
\hline & $\mathrm{N}$ & 160 & 160 & 160 & 160 & 160 & 160 & 160 & 160 & 160 \\
\hline \multirow{3}{*}{ FBSNm } & $\begin{array}{c}\text { Pearson } \\
\text { Correlation }\end{array}$ & -.104 & $.319^{*}$ & $.367^{*}$ & .166 & .221 & 1 & $.932^{* *}$ & .068 & -.120 \\
\hline & $\begin{array}{c}\text { Sig. } \\
\text { (2-tailed) }\end{array}$ & .522 & .045 & .020 & .307 & .170 & & .000 & .678 & .460 \\
\hline & $\mathrm{N}$ & 160 & 160 & 160 & 160 & 160 & 160 & 160 & 160 & 160 \\
\hline \multirow{3}{*}{ FBFNm } & $\begin{array}{c}\text { Pearson } \\
\text { Correlation }\end{array}$ & -.132 & .213 & .300 & .151 & .230 & $.932^{* *}$ & 1 & .144 & -.100 \\
\hline & $\begin{array}{c}\text { Sig. } \\
\text { (2-tailed) }\end{array}$ & .417 & .186 & .060 & .352 & .154 & .000 & & .376 & .540 \\
\hline & $\mathrm{N}$ & 160 & 160 & 160 & 160 & 160 & 160 & 160 & 160 & 160 \\
\hline \multirow{3}{*}{ AHSNm } & $\begin{array}{c}\text { Pearson } \\
\text { Correlation } \\
\end{array}$ & -.050 & -.248 & -.160 & -.011 & .052 & .068 & .144 & 1 & $.634^{* *}$ \\
\hline & $\begin{array}{c}\text { Sig. } \\
\text { (2-tailed) }\end{array}$ & .761 & .124 & .325 & .949 & .749 & .678 & .376 & & .000 \\
\hline & $\mathrm{N}$ & 160 & 160 & 160 & 160 & 160 & 160 & 160 & 160 & 160 \\
\hline \multirow{3}{*}{ AHFNm } & $\begin{array}{c}\text { Pearson } \\
\text { Correlation } \\
\end{array}$ & -.294 & $-.456^{* *}$ & -.130 & .086 & .056 & -.120 & -.100 & $.634^{* *}$ & 1 \\
\hline & $\begin{array}{c}\text { Sig. } \\
\text { (2-tailed) }\end{array}$ & .066 & .003 & .425 & .600 & .733 & .460 & .540 & .000 & \\
\hline & $\mathrm{N}$ & 160 & 160 & 160 & 160 & 160 & 160 & 160 & 160 & 160 \\
\hline
\end{tabular}

*. Correlation is significant at the 0.05 level (2-tailed).

**. Correlation is significant at the 0.01 level (2-tailed).

$N=$ distribution; BMI=Body Mass Index; FLN=Foot length non-weight bearing; FLS=Foot length semi-weight bearing; FLF=Foot length full-weight bearing; FLSN=change in foot length of semi-weight bearing condition; FLFN=change in foot breadth of fullweight bearing condition; $F B=$ Foot breadth; $A H=$ Arch Height; $f=$ female

\section{DISCUSSION}

In this study, the effect of BMI on foot dimensions under the different weight bearing conditions were analysed using the feet of three hundred and twenty volunteers which comprised of 160 males and 160 females in Obokwe, Imo state.

This study reveals that foot dimensions were observed to have sexual dimorphic characteristic in significantly higher values in males than females. Many of the measured parameters showed high sex difference as observed by (Sween et al., 2016; Reena et al., 2012; Oladipo et al., 2008).
The difference in the height, weight, FLN, FLS, FLF, FBN, FBS, FBF, AHN, AHS and AHF of male and female was highly significant $(\mathrm{p}<0.05)$, while other parameters such as (BMI, FLSN, FLFN, FBSN, FBFN, AHSN and AHFN) were not significant.

This study also showed that the change in foot length of males is statistically greater than that of the females and this agrees with the previous findings of Oladipo et al., (2008). Also, the change in foot breadth and arch height $\mathrm{AH})$ of males is statistically greater than that of the females $(\mathrm{p}<0.05)$. 
BMI showed a highly significant correlation with height weight and AHSN at 0.01 level and also showed statistical significant correlation with FLFN and AHFN at 0.05 level for females. This study showed that BMI has a highly statistical significant correlation with height and weight at 0.01 level and also showed statistical significant correlation with FBSN at 0.05 level for males. The BMI of females had more correlation with foot dimensions than the BMI of the males. This finding agrees with the works of Aurichio et al., (2011) and Reihaneh et al., (2013) but disagrees with that of Ashwini et al. (2015). This could be is a result of higher BMI values noted among the females in the study.

\section{CONCLUSION}

Some foot dimensions can be significantly influenced by BMI. Therefore, this study is useful in considering the effect of BMI in the change of foot dimensions in weightbearing during the selection of shoe (shoe size) or insole design and construction. It is beneficial to the orthotics during the design of fitting devices for foot support. Also, it can be useful in forensic science.

\section{REFERENCES}

[1] Ashwini C., Visit P., Erohit K., \&Sudipita P. (2015). Screening of Body Mass Index and Functional Flatfoot in Adults: An observational study. International Journal of Physiotherapy and Research, 3(3):1037-1041

[2] Aurichio T.R., Rebelatto J.R \& De Castro, A.P. (2011). The relationship between the body mass index (BMI) and foot posture in elderly people. Archives of Gerontology and Geriatrics, 52(2): 89-92.

[3] Benninghoff A. (1949). Lehrbuch der Anatomie des Menschen. Urban and Schwarezenberg, BerlinMünchen.

[4] Body Mass Index - Scientific Figure on ResearchGate. Available from:

https://www.researchgate.net/figure/Body-MassIndex-Chart-WHO_fig4_310447991 [accessed 1 Nov, 2019].

[5] Bonnie, S.T., Ming, S., Yu, B. \& David, A.B. (2003) Quantitative comparison of plantar foot shapes under different weight-bearing conditions. Journal of rehabilitation research and development. 40(6): 517-26. doi:10.1682/JRRD.2003.11.0517.

[6] Butterworth, P.A., Landorf, K.B., Smith, S.E. \& Menz H.B. (2012). The association between body mass index and musculoskeletal foot disorders: a systematic review. Obesity Review, 13: 630-642. doi:10.1111/j.1467-789X.2012.00996.

[7] Dowling, A., Steele, J. \& Baur, L. (2001). Does obesity influence foot structure and plantar pressure patterns in prepubescent children? International Journal of Obesity Related Metabolism Disorders, 25: 845-852.
[8] Gilmour, J.C \& Burns, Y. (2001). The measurement of the medial longitudinal arch in children. International Orthopedic Foot Ankle Society. 22: 493-498.

[9] Gravante, G., Russo, G., Pomara, F. \& Ridola, C. (2003). Comparison of ground reaction forces between obese and control young adults during quiet standing on a baropodometric platform. Clinical Biomechanics, 18: 780-782.

[10] Hills, A.P., Hennig, E.M., Byrne, N.M. \& Steele, J.R. (2002). The biomechanics of adiposity - structural and functional limitations of obesity and implications for movement. Obesity Review, 3: 35-43.

[11] Jelinek, H.F. \& Fox, D. (2009). Foot Health and Elevated Body Mass Index. Foot Ankle Online Journal. doi:10.3827/faoj.2009.0208.0004.

[12] Keys, A., Fidanza, F., Karvonen, M., Kimura, N. \& Taylor, H. (1972). Indices of relative weight and obesity. Journal of chronic diseases. 25(6): 329-43.

[13] Mickle, K.J., Steele, J.R. \& Munro, B.J. (2006). The Feet of Overweight and Obese Young Children: Are They Flat or Fat? Obesity, 14: 1949-1953. doi:10.1038/oby.2006.227.

[14] Oladipo, G., Bob-Manuel I.F.\& Ezenatein, G. (2008). Quantitative comparison of foot anthropometry under different weight bearing conditions amongst Nigerians. The Internet Journal of Biological Anthropology, 3(1): 4-9.

[15] Park, J. (2012). Gauging the Emerging Plus-Size Footwear Market: An Anthropometric Approach. Clothing and Textile Research Journal doi:10.1177/0887302X12469291.

[16] Price, C. \& Nester, C. (2015). Is retail footwear fit for purpose for the feet of adults who are obese? Footwear Science. 7:146-147. doi:10.1080/19424280.2015.1039077.

[17] Reena S., Minu B.\& Mrinal B. (2012). Sex estimation from foot anthropometry in Haryanvi Jats and north Indian mixed population. Journal of Social, Behavioral, Educational, Economic, Business and Industrial Engineering, 5(12): 1928-1933.

[18] Reihaneh, A.K., Faranak, A. \& Mostafa, G. (2013). Prevalence of Flatfoot: Comparison between male and female primary school students. Iranian Rehabilitation Journal, 11(18): 22-24.

[19] Riddiford-Harland, D.L., Steele, J.R. \& Baur, L.A. (2011). Foot structure in obese children: Implications for footwear design. Obesity Research in Clinical Practice, 5: 36-36.

[20] Sween, W., Bhawani, S.M. \& Nishi, P. (2016). Sexual dimorphism from foot dimensions and footprints in Haryanvi Jat population. International Journal of Anatomy and Research, 4(1): 2142-2147. 